\title{
Improving Communication Ability And Mathematical Self Efficacy Of Elementary School Students Through The Realistic Mathematics Learning Approach
}

\author{
Sakinah Ubudiyah Siregar, Eva Julyanti, Jainir Efendi Siregar, Ronal Watrianthos
}

\begin{abstract}
The research activity was focused on improving communication skills and mathematical self-efficacy of students who obtained realistic mathematics learning approaches in elementary schools. The purpose of the study was to determine the improvement of communication skills and mathematical self efficacy of students who obtained realistic mathematics learning approaches better than students' mathematical communication skills who obtained a conventional approach. Improvement of communication skills and mathematical self efficacy of students who get a realistic mathematics learning approach will be conducted through a study of action studies on the subject of research namely elementary students in several schools around Rantauprapat City. Therefore the research that would be used was following a series of quasi-experimental studies. The results of the calculation of the two-way ANOVA calculation of the post-test minimum self-efficacy scores of students in the class given a realistic approach were 58.0 better than students in the class given conventional learning 43.0, as well as the maximum self-efficacy scores of students in the class given a realistic approach 69 , 0 is better than students who were given conventional learning 58.0, thus with a posttest self-efficacy score for the class given a realistic approach 62.633 higher than the posttest average of students for the class given conventional learning 49.667 and a significant level of 0.000 . In order that significant $0,000<0,05$ means $\mathrm{H} 0$ is rejected so it could be concluded that the increase in mathematical communication skills of students with realistic approaches is higher than students given conventional learning.
\end{abstract}

Index Terms: Communication Skills, Self Efficacy, Realistic Mathematics, Learning Approaches

\section{INTRODUCTION}

Mathematical skills that are grown in mathematics learning such as reasoning, communication, connection, and problem solving are mathematical contributions to the achievement of life skills that are needed by students in the real world. One of the five standard processes The principles and standards of NCTM are communication can help students learn about new mathematical concepts when they portray drawing situations using objects, provide reports and verbal explanations. Also when using diagrams, writing and using mathematical symbols[1]. Thus a number of experts have defined the notion of principles and standards of mathematical communication [1] suggesting mathematics as a communication tool (mathematics as cummunication) was the development of languages and symbols to communicate mathematical ideas, so students could be: (1) express and explain their thoughts about mathematical ideas and their relationships, (2) formulate mathematical definitions and make generalizations obtained through investigation (discovery), (3) express mathematical ideas verbally and in writing, (4) bring mathematical discourse with understanding, (5) explain and express and expand the questions on mathematics that have been learned, (6) appreciate the beauty and power of mathematical notation, and its role in developing mathematical ideas / ideas. In addition to the amount of research in cognitive aspects, in the last 20 years the affective aspects have been explored by researchers, including self-efficacy (almost identical to 'selfconfidence') which was expected to improve students' mathematical abilities. self-efficacy institutionalizes a key component in Bandura's cognitive cognitive theory. Building signifies a person's confidence, about his ability to successfully carry out a task. It was found that self-efficacy is a major choice factor for individual development, perseverance in using various difficulties, and pattern thinking and emotional reactions they experience[2]. Self efficacy could be generated from students through four sources, namely (1) authentic experience (authentic mastery experiences), (2) other people's experiences (vicarious experience), (3) social or verbal approach (verbal persuasion), (4) psychological aspects (physiological affective states). In learning (especially mathematics), a teacher must be able to choose a learning strategy (approach) that was appropriate to the stage of children's intellectual development, in order that it affects children's learning outcomes. One of the learning approaches that are in line with these changes is the Realistic Mathematics Learning (RML) approach. RML is an approach in mathematics learning that views mathematics as a human activity. This statement departs from the opinion of Fruedenthal that mathematics is a human activity and must be associated with reality[3]. Mathematical learning could not be separated from the mathematical nature of someone solving problems, finding problems, and organizing or mathematical subject matter. From the description above, researchers tried to conduct research by applying communication skills and mathematical self-efficacy through elementary students through realistic mathematical learning approaches. It was expected that the improvement of communication and self-efficacy skills with realistic mathematics learning approaches was better than students' mathematical communication skills with conventional approaches..

\section{ReseaRch Method}

This study was used a quantitative research approach with experimental methods in the form of quasi-experiments. Experimental research is research really to look at causal relationships[4]. The treatment that we do with our independent variables was tofind the results in the dependent variable.This purpose of this study to examine communication skills, self efficacy, and the process of solving student answers that were influenced by learning approaches namely Realistic Mathematics Learning (RML) and Conventional Mathematics Learning (CML). This study taken two representative random parallel classes from pupolation by applying different learning. The first class (first group) was treated by applying a realistic mathematics learning approach and the second class (second 
group) was not treated only by conventional learning.

Table 1. Research Design

\begin{tabular}{|c|c|c|c|}
\hline Treatment Group & Pretest & Treatment & Posttest \\
\hline $\begin{array}{c}\text { Realistic Mathematics } \\
\text { Learning (Experiment) }\end{array}$ & $\mathrm{O}$ & $\mathrm{X}$ & $\mathrm{O}$ \\
\hline Convensional (Control) & $\mathrm{O}$ & & $\mathrm{O}$ \\
\hline
\end{tabular}

Notes:

$$
\begin{array}{ll}
\mathrm{O} & : \text { Pretest dan Posttest } \\
\mathrm{X} & \text { : The treatment approaches } \\
& \text { realistic mathematics learning }
\end{array}
$$

\section{RESULT AND DISCUSSION}

This research was conducted in three stages, namely the implementation of pretest, implementation of learning and implementation of posttest. This research was conducted in the even semester in class IV SD Negeri Rantauprapat from June 13, 2016 to June 25, 2016. All the classes, two classes were chosen from SD Negeri 116874 was IV A and IV B for the experimental class there were 30 people and two classes from SD Negeri 112134 Rantauprapat namely classes IV A and IV B for the control class totaling 30 people.

\subsection{Implementation of the Pretest}

At the first meeting, the two classes were given a pretest to measure students 'mathematical communication skills and questionnaires to measure students' self-efficacy. The implementation of the pretest begins with students first working on the communication skills test then proceeding to fill out the self-efficacy questionnaire.

\section{a. The Results Pretest Student Mathematical} Communication Ability Test

The obtain a pretest test of students' mathematical communication skills, a mean and standard deviation calculation was performed. The summary results werepresented in Table 2. Below

Table.2 Description of Pretest Mathematical Communication Ability Tests Students Based on Learning Report

\begin{tabular}{lccccc}
\hline & \multicolumn{5}{c}{ PRETEST } \\
\hline Class & $\mathbf{N}$ & Min & Max & Mean & Std Deviation \\
\hline Experiment & 30 & 7,0 & 13,0 & 10,166 & 1,3668 \\
Control & 30 & 6,0 & 12,0 & 9,134 & 1,4076 \\
Total & 60 & 6,0 & 13,0 & 9,651 & 1,4708
\end{tabular}

From Table 2 the number of students for the experimental and control classes was 30 people, the maximum score of mathematical communication skills of students in the class using a realistic approach was 13.0 higher than those given with conventional learning 12.0, the minimum score of students' mathematical communication pretest in class who were given a realistic approach higher 7.0 than students in the class given conventional learning 6.0, the mean score of the pretest of mathematical communication skills for the class given a realistic approach was 10.166 higher than the average pretest of students for the class given with conventional learning 9,134 , but the standard deviation of the students' pretest in mathematical communication skills for the class given a realistic approach of 1.3668 was lower than the standard deviation of mathematical communication pretest for the class given conventional learning 1.4708 .

\section{b. The Results of Student's Self Efficacy Pretest}

To obtain a pretest self-efficacy description of students, a mean and standard deviation calculation was performed. The summary results were-presented in Table 3 below:

Table.3 Description of Self Efficacy Questionnaire Pretest Students Based on Learning Report

\begin{tabular}{lccccc}
\hline & \multicolumn{5}{c}{ PRETEST } \\
\hline Class & $\mathbf{N}$ & Min & Max & Mean & Std Deviation \\
Experiment & 30 & 32,0 & 47,0 & 37,900 & 3,7439 \\
Control & 30 & 29,0 & 45,0 & 35,834 & 3,8414 \\
Total & 60 & 29,0 & 47,0 & 36,866 & 3,9024
\end{tabular}

From Table 3 the number of students was 30 people for the experimental and control classes, the maximum score of selfefficacy of students in the class given a realistic approach is 47.0 better than students in the class given conventional learning 45.0, the minimum score of students' self-efficacy in class who were given a realistic approach 32.0 better than students in the class given conventional learning 29.0, the mean score of self-efficacy pretest for the class given a realistic approach 37,900 was better than the average pretest for the class given conventional learning 35,834 , but the standard deviation students' pretest in self-efficacy for the class given a realistic approach of 3.7439 was lower than the standard deviation of the self-efficacy pretest for the class given conventional learning 3.8414 .

\subsection{Learning Implementation}

\section{a. Implementation of Learning with Realistic Approach}

As a reference for the course of the learning process, researchers follow a lesson plan that has been prepared in accordance with the syntax of the Realistic Approach. First, students were given a real problem related to the everyday world of students or knowledge that students have learned in the form of LAS. Learning with a realistic approach is implemented at SD 116874 class IV A and IV B, with many students 30 people, consisting of 11 male students and 19 female students. Learning begins with group formation and the introduction of realistic learning and its syntax. The 30 students 6 groups were formed consisting of male and female and headed by class ranking. In groups students discuss working on the LAS and make a model of what fits the concept. Students were free to make a model of them that was considered able to solve problems with the LAS. The next step, one group presents the results of the group discussion.Other groups may ask questions and respond to the answers of the presenter groups. From the various models of students made, the teacher directs the students to the correct conclusions, so it was concluded a correct concept that was the model for.

\section{b. The Results Posttest of Student Mathematical Communication Ability Tests}

In order to obtain a posttest description of the students' mathematical communication skills, a mean and standard deviation calculation was performed. The summary results were-presented in Table 4 below: 
Table.4 Description of Postest Mathematical Communication Ability Test Students Based on Learning Report

\begin{tabular}{lccccc}
\hline & \multicolumn{5}{c}{ POSTTEST } \\
\hline Class & $\mathbf{N}$ & Min & Max & Mean & Std Deviation \\
\hline Experiment & 30 & 22,0 & 30,0 & 26,200 & 1,9101 \\
Control & 30 & 19,0 & 24,0 & 21,800 & 1,4320 \\
Total & 60 & 19,0 & 30,0 & 23,800 & 2,7682
\end{tabular}

Table 4 the number of students in the experimental class and control of 30 people, the maximum score of mathematical communication skills of students in the class given a realistic approach 30.0 higher than students given learning 24.0, the minimum posttest score of mathematical communication skills of students in the class given the approach realistic 22.0 higher than students in the class given conventional learning 19.0, posttest average mathematical communication skills for the class given a realistic approach 26,200 higher than the posttest average of students for the class given learning 21,800 , the standard deviation of posttest students in Mathematical communication skills for classes given a realistic approach were 1.9101 higher than the standard deviation of mathematical communication postes for classes given conventional learning 1.4320 .

\section{b. The Results of Student Self-Efficacy Postest}

To obtain a posttest self-efficacy of students, a mean and standard deviation calculation was performed. The summary results were-presented in table 5 below:

Table.5 Description of Students Self Efficacy Posttest Based on Learning Report

\begin{tabular}{lccccc}
\hline & \multicolumn{5}{c}{ POSTTEST } \\
\hline Class & $\mathbf{N}$ & Min & Max & Mean & Std Deviation \\
\hline Experiment & 30 & 58,0 & 69,0 & 62,633 & 2,3059 \\
Control & 30 & 43,0 & 58,0 & 49,667 & 3,4977 \\
Total & 60 & 43,0 & 59,0 & 56,250 & 7,1995
\end{tabular}

Table 5 of the posttest self efficacy scores of students in the class given a realistic approach was 58.0 better than students in the class given conventional learning 43.0, as well as the maximum self-efficacy score of students in the class given a realistic approach 69.0 was better than students who were given conventional learning 58.0, thus with a posttest self efficacy score for the class given a realistic approach 62.633 higher than the posttest average students for the class given conventional learning 49.667, but the post-standard standard deviation of students in self efficacy for the class given approach realistic 2.3059 lower than the standard post-self self efficacy deviation for classes given conventional learning 3.497. From the results of the calculation, the increase in mathematical communication skills of students who were given a realistic approach was higher than students who were given conventional learning. Students who take part in learning with a realistic approach were accustomed to being active in solving problems thinking individually to get concepts. In that the learning process was not just transferring knowledge from the teacher to students, but rather a process that was conditioned or sought by the teacher, so students were active in various ways to build their own knowledge. In line with Piaget who emphasized the importance of student motivation and facilitation by the teacher. In order for children's intellectual development to take place optimally, they need to be motivated and facilitated to develop theories that explain the world around. In a realistic approach the teacher was required to facilitate and encourage students to be actively involved in the learning process so that they were able to construct knowledge for themselves. The results of the calculation of two-way ANOVA on the N-Gain score of the realistic approach and conventional learning groups obtained the $F$ value of the learning factor of 100,123 and the significant level of 0,000 . In that significant $0,000<0,05$ means Howas rejected so it could be concluded that the increase in mathematical communication skills of students with realistic approaches was higher than students given conventional learning.

\section{CONCLUSION}

Based on the results of data analysis on the average pretest and posttest scores in the realistic approach and conventional learning groups, the $F$ value of the learning factor was obtained at 100,123 and a significant level of 0,000 .In that significant $0,000<0,05$ means that Howas rejected so it could be concluded that the increase in students' mathematical communication skills with realistic approaches was higher than students given conventional learning.

\section{REFERENCES}

[1]. J. . Van de Walle, Development of Primary and Secondary School Teaching Mathematics Sixth Edition Volume I. 2008.

[2]. A. Bandura, "Self-Efficacy," Encycl. Hum. Behav. (Vol., vol. 4, no. 1994, pp. 71-81, 1994.

[3]. Turmudi, Philosophical Foundation and Mathematical Learning Theory (Explorative and Investigative Paradigm. Jakarta: PT Leuser Cita Pustaka, 2008.

[4]. E. Ruseffendi, Introduction to Helping Teachers Develop Competencies in Teaching Mathematics to Improve CBSA. bandung: Tarsito, Bandung, 2005. 